\title{
Peritoneal Carcinomatosis: Registry and Centers in Germany
}

\author{
Jörg O. W. Pelz
}

Department of General-, Visceral-, Vascular- and Pediatric Surgery, Julius-Maximilians University Wuerzburg, Germany

\section{Keywords}

Peritoneal carcinomatosis - German HIPEC registry . Accreditation

\section{Summary}

Background: At present, there are only few objective quality criteria for the treatment of peritoneal carcinomatosis using cytoreductive surgery and hyperthermic intraperitoneal chemoperfusion (HIPEC). Method and Results: However, because this therapy is associated with significant morbidity and mortality, such quality criteria are quite important. Accreditation of peritoneal carcinomatosis centers by the German Society for General and Visceral Surgery was a first step towards establishing these clinics. Conclusion: One key requirement for accreditation is membership in the German Peritoneal Carcinomatosis Registry. This prospective database provides a collation and evaluation of the epidemiological and therapeutic factors relating to this disease.

\section{Introduction}

The usefulness of surgical treatment in the management of peritoneal carcinomatosis is more controversial than for virtually any other oncology condition.

For patients, the journey to a medical center that specializes in the treatment of peritoneal carcinomatosis is often a long one. Frequently, the individuals involved find out too late about treatment options. New developments in the field of chemotherapeutics and options for surgery or radiation continue to arise. Clinical and scientific evaluation and closer examination of treatments and treatment results have timely implications for the procedures of the future.
Schlüsselwörter

Peritonealkarzinose - Deutsches HIPEC-Register . Zertifizierung

\section{Zusammenfassung}

Hintergrund: Für die Behandlung der Peritonealkarzinose mittels zytoreduktiver Chirurgie und hyperthermer intraperitonealer Chemoperfusion (HIPEC) gibt es derzeit nur wenige objektive Qualitätskriterien. Methode und Ergebnisse: Da diese Therapie mit einer nicht unerheblichen Morbidität und Letalität einhergeht, sind diese Qualitätskriterien jedoch sehr wichtig. Mit der Akkreditierung von Peritonealkarzinosezentren über die Deutsche Gesellschaft für Allgemein- und Viszeralchirurgie wurde ein erster Schritt unternommen, Peritonealkarzinosezentren abzubilden. Schlussfolgerung: Eine wichtige Voraussetzung für die Akkreditierung ist die Beteiligung am deutschen Peritonealkarzinoseregister. In dieser prospektiven Datenbank werden epidemiologische und therapeutische Faktoren dieser Erkrankung gesammelt und ausgewertet.

For each patient, it is essential to find a customized treatment for which the risks and chances of success are balanced according to the latest findings.

\section{Cytoreductive Surgery and Hyperthermic Intraperitoneal Chemoperfusion: The Learning Curve is Long but Essential!}

With respect to a combination treatment using cytoreductive surgery (CRS) and hyperthermic intraperitoneal chemoperfusion (HIPEC), the literature reports increased rates of peri- and postoperative morbidity (15-70\%) and mortality

Prof. Dr. med. Jörg Pelz

Department of General-, Visceral-, Vascular- and Pediatric Surgery Julius-Maximilians University Wuerzburg

Oberdürrbacher Str. 6, 97080 Würzburg, Germany

pelz_j@klinik.uni-wuerzburg.de 
(0-11\%) [1-9]. A review by Chua et al. [10] revealed a level $3 / 4$ morbidity of $28.8 \%$, with $11.2 \%$ of the patients requiring further surgery. Mortality was reported as $2.9 \%$. This mortality is no higher than for other major oncological surgeries such as gastrectomy. At the same time, however, a potentially slightly smaller gain in time should not be exchanged for a poorer quality of life. After all, only very few of these patients are treated with curative intent.

Further, analyses have shown that the various complications can be significantly reduced below the learning curve once the procedure is established and has undergone repeated trials [2, 4, 8, 11, 12]. Smeenk et al. [4] described an improvement of CC-0 resection (complete macroscopic removal of the tumor) from 35.6 to $65.1 \%$ within 10 years. Over the same period, morbidity was reduced from 71.2 to $34.1 \%$ and the average hospital stay was reduced from 21 to 17 days. The authors attribute these results to a long-term learning effect, such that up to 130 procedures must be performed until it is safely established.

Yan et al. [2] were able to establish a reduction of the level $3 / 4$ morbidity from 30 to $10 \%$ after carrying out $140 \mathrm{CRS}$ and HIPEC treatments, when comparing a group of patients receiving first treatment $(\mathrm{n}=70)$ with a second patient group $(\mathrm{n}=70)$. Moreover, there were advantages for the second patient group in terms of transfusions required, the length of the surgery, and the length of stay in intensive care.

An additional two studies [11, 12] and one overview [13] were able to document similar and consistent results. Moran et al. [11] suggested that optimization of the results could be achieved using improved decision-making and considering key technical variables.

González Bayón et al. [8] also pointed out that, in addition to careful planning and preparation, an engaged and specially trained team and appropriate equipment can facilitate a smooth procedure.

Focused preparation, optimization of the surgical techniques and the HIPEC setup, intensification of interdisciplinary collaboration under increased sensitization of the medical and support staff for a new treatment strategy, as well as patient selection and treatment options that are targeted according to oncological considerations are all factors that are just as important as the surgical skills of the surgeon.

\section{Is the Establishment of HIPEC Centers Useful?}

Unlike other countries, Germany is currently experiencing a boom in terms of multimodal treatment for peritoneal carcinomatosis. Initially demonized and for many years carried out by only a few clinics, after the publication of the first promising studies, it has become increasingly 'modern' to include this procedure within a treatment portfolio. The forces behind this trend are likely to be found in the marketing field in being able to offer something new ('beyond the borders') and in the surgical challenge taken up by some colleagues. Indeed, a certain marketing effect and the public image are probably also important factors.

Unfortunately, the quality of treatment and especially the acceptance of the generally critically inclined oncological treatment partner are compromised under these terms. A mortality of up to $10 \%$ and a $3 / 4$ morbidity of up to $50 \%$ indicate the problems associated with this treatment. The fact also remains that these patients are mostly in a palliative situation. Accepting that the patient has nothing to lose is out of the question. In addition to the importance of quality of life, the loss of time until the beginning of the necessary palliative chemotherapy plays a key role.

The usefulness of the formation of centers is a controversial topic in this regard. Naturally, a certain degree of external control is important. However, it can only be fruitful if specific quality markers are used for review. These markers are lacking. Thus, for example, the completeness of cytoreduction score (CC score) for determining the surgical radicality is, as described earlier, subjective since the score is determined by the surgeon himself. Insisting on interdisciplinarity, on morbidityand-mortality conferences, and on a lower mortality is a first step, but not sufficient. Ultimately, the operational approach must be measured against the conservative methods. Considering the complications that cannot be ignored, there must be a clear advantage compared to systemic chemotherapy. In the treatment of peritoneal metastatic colorectal cancer, a mean survival time of 36 months was thus claimed. On the downside, the surgical quality or patient selection is not sufficient.

Training of the team is essential. For example, practical suggestions and a first exchange of experience can take place via guestings at national and international centers for HIPEC. However, it is not advisable to start a 'center' after a 1-day guest visit. Clearly, the model of some foreign centers, which offer a fellowship for 1 or 2 years, is a better approach. Further, careful planning should extend to the level of the clinic, where the local infrastructure must be adapted and the medical and support personnel must be trained taking into account the acquired skills.

Among other effects, certified centers serve to market a clinic and enhance the service portfolio. For several years already, the German health care system has seen a constantly growing number of centers being registered. Particularly in the complex interdisciplinary care of oncology patients, the decision is often made to concentrate the processes under the single roof of a center. This applies also to peritoneal carcinoma centers.

For the layperson, a center always signifies high quality. However, since the term is not protected, this is not necessarily the case.

Rather, the quality of a center is confirmed by certification. Thus, various parameters are evaluated in the context of a certification. These involve the structure of the care, the setup of the center, and the medical expertise and quality. 
The term 'peritoneal carcinoma center' is similarly not protected. Until now, there has also been no procedure for certification as it is used, e.g., for 'colorectal cancer centers'. Instead, some clinics in Germany have banded together under the umbrella of the DGAV (Deutsche Gesellschaft für Allgemein- und Viszeralchirurgie = German Society for General and Visceral Surgery), to obey self-imposed specific quality guidelines.

\section{Accreditation of HIPEC Centers}

Since 2013, a 'Center of Excellence for Surgical Treatment of Malignant Diseases of the Peritoneum' can now also be certified via the SAVC (Servicegesellschaft für Allgemeinund Viszeralchirurgie $=$ Service Company for General and Visceral Surgery). The first four centers were successfully certified in Germany in April 2013.

This process involved a project group consisting of experienced specialists who prepared a certification catalog that was aligned with the SAVC and members of the organ group.

To qualify as a center of competence for 'Surgical Treatment of Malignant Diseases of the Peritoneum', the following criteria must be met:

- At least two visceral surgeons must have at least 2 years' experience with multimodal treatment of peritoneal carcinomatosis.

- There must be a defined structural organization. In addition to a specific consultation clinic, this includes the examination of all patients before the interdisciplinary tumor board and the application of a specialized interdisciplinary pain therapy.

- Requirements in terms of personnel and equipment are in place to ensure comprehensive diagnostics and interventional treatment for $24 \mathrm{~h}$ daily. Similarly, there has to be a suitable, certified pump for performing HIPEC.

- There is interdisciplinary cooperation among gastroenterologists, gynecologists and internal oncologists in leadership and senior physician roles. Interdisciplinary intensive medical care with the option for dialysis is in place.

- At least 15 parietal and visceral peritonectomies using HIPEC are performed annually. In addition, annually, at least 50 patients with a peritoneal carcinomatosis must be evaluated by a special tumor board.

- Each listed surgeon must partake annually in at least one advanced training course on this subject.

- A record of patient information must be kept that includes morbidity and mortality data (postoperative hemorrhaging, abscesses, leaking of bile, sepsis, nonsurgical complications), the frequency at which further surgery is required, reintervention rates, and the duration of hospitalization. The data entry must take place taking into account the data protection regulations of the HIPEC registry of the DGAV.
The point regarding minimum case numbers has even been subject to controversial discussion. It is known that in certain fields, such as colorectal surgery, quality decreases with increasing case numbers $[14,15]$. With the lack of concrete quality markers for HIPEC treatment, there is indeed the danger of 'false' indications associated with a minimum number that is set too high. For this reason, assessment of quality puts particular emphasis on the evaluation of clinical and epidemiological data.

\section{The German HIPEC Registry}

Detailed documentation is essential not only for continuous improvement but also in order to facilitate the measurement and communication of the work and its quality. Therefore, a registry is an obvious medium with which to present the quality of surgical treatment of peritoneal carcinomatosis.

Medical registries are characterized by compilations of standardized documentation of specific medically delimited examinations or treatment collectives.

In Germany, each cancer registry is located within the individual state in which the population is examined. The first cancer registry was established in Hamburg in 1926. The development of each cancer registry advances to an extent that differs from state to state. The data are evaluated nationally at the Center for Cancer Registry Data at the Robert Koch Institute.

There are two basic types of cancer registries. The primary function of the epidemiological cancer registry is examination of the rates of occurrence of tumor diseases and their frequencies in a defined region. However, this type of registry is not suitable for identifying the quality of a new method, such as CRS and HIPEC.

In contrast, the clinical cancer registry focuses on ongoing improvement in the treatment of tumor diseases. This focus involves not only the assimilation of detailed information about diseases and diagnoses but also the comparison of specific treatment procedures. In particular, this type of registry can record complications in the form of morbidity and mortality as well as potential treatment successes.

In order to improve the quality of peritonectomy and HIPEC treatment in Germany and to be able to better comprehend the disease progression in these patients, the 'Peritoneum' organ group of the CAO-V (German Society of Surgical Oncology) initiated the HIPEC German Registry. The goal of this database is to record the key criteria of patients with peritoneal carcinomatosis. This database now provides the opportunity for multi-institutional observations with a large number of patients, which would not be possible within a single clinic.

An HIPEC registry already exists in the French-speaking community. Results have already been published in several instances [16-19]. Key findings in the field are provided. Be- 
cause it is quite challenging to initiate randomized studies, these publications are very important for the improvement of treatment.

Because the existing German clinical cancer registries consist only of standardized surveys, it was necessary to develop a registry specifically customized for this disease. The NOTES registry, which had already been established by the DGAV, served as a basis. This registry was adapted to the specific needs of peritoneal carcinomatosis and its treatment. Thus, specific key aspects of HIPEC, such as temperatures, treatment duration, or perfusion techniques, as well as the disease, are included in the database. At present, almost 1,500 patients are reported in the registry. The first evaluation will take place once the data is complete and a follow-up will occur after at least 18 months. At present, the data are incomplete, and for this reason, an interpretation of the data is not useful at this time.

\section{Conclusion}

CRS in association with HIPEC is a procedure with relatively high morbidity and mortality. In order to improve the quality of treatment, a multimodal therapy should be carried out within an interdisciplinary center. Because the term 'center' is not protected, in the future, accreditation of these institutions will take place.

\section{Disclosure Statement}

No conflicts of interest.

\section{References}

1 Glehen O, Osinsky D, Cotte E, Kwiatkowski F, Freyer G, Isaac S, Trillet-Lenoir V, Sayag-Beaujard AC, Francois Y, Vignal J, Gilly FN: Intraperitoneal chemohyperthermia using a closed abdominal procedure and cytoreductive surgery for the treatment of peritoneal carcinomatosis: morbidity and mortality analysis of 216 consecutive procedures. Ann Surg Oncol 2003;10:863-869.

2 Yan TD, Links M, Fransi S: Learning curve for cytoreductive surgery and perioperative intraperitoneal chemotherapy for peritoneal surface malignancy - a journey to becoming a Nationally Funded Peritonectomy Center. Ann Surg Oncol 2007;14:2270-2280.

3 Moran BJ, Mukherjee A, Sexton R: Operability and early outcome in 100 consecutive laparotomies for peritoneal malignancy. Br J Surg 2006;93:100104.

4 Smeenk RM, Verwaal VJ, Zoetmulder FA: Learning curve of combined modality treatment in peritoneal surface disease. Br J Surg 2007;94:1408-1414.

$\checkmark 5$ Jacquet P, Stephens AD, Averbach AM, Chang D, Ettinghausen SE, Dalton RR, Steves MA, Sugarbaker PH: Analysis of morbidity and mortality in 60 patients with peritoneal carcinomatosis treated by cytoreductive surgery and heated intraoperative intraperitoneal chemotherapy. Cancer 1996;77: 2622-2629.

6 Stephens AD, Alderman R, Chang D, Edwards GD, Esquivel J, Sebbag G, Steves MA, Sugarbaker PH: Morbidity and mortality analysis of 200 treatments with cytoreductive surgery and hyperthermic intraoperative intraperitoneal chemotherapy using the coliseum technique. Ann Surg Oncol 1999;6:790-796.
7 Esquivel J, Vidal-Jove J, Steves MA, Sugarbaker PH: Morbidity and mortality of cytoreductive surgery and intraperitoneal chemotherapy. Surgery 1993;113:631-636.

8 González Bayón L, Sugarbaker PH, Gonzalez Moreno S, Vazquez Vde L, Alves S, Moran BJ: Initiation of a program in peritoneal surface malignancy. Surg Oncol Clin N Am 2003;12:741-753.

-9 Mohamed F, Moran BJ: Morbidity and mortality with cytoreductive surgery and intraperitoneal chemotherapy: the importance of a learning curve. Cancer 2009:15:196-199.

10 Chua TC, Yan TD, Saxena A, Morris DL: Should the treatment of peritoneal carcinomatosis by cytoreductive surgery and hyperthermic intraperitoneal chemotherapy still be regarded as a highly morbid procedure? A systematic review of morbidity and mortality. Ann Surg 2009;249:900-907.

11 Moran BJ: Decision-making and technical factors account for the learning curve in complex surgery. J Public Health (Oxf) 2006:28:375-378.

12 Cavaliere F, Valle M, De Rosa B, et al: Peritonectomy and chemohyperthermia in the treatment of peritoneal carcinomatosis: learning curve. Suppl Tumori 2005;3:119-121.

13 Moradi BN 3rd, Esquivel J: Learning curve in cytoreductive surgery and hyperthermic intraperitoneal chemotherapy. J Surg Oncol 2009;100:293-296.

14 Prystowsky JB, Bordage G, Feinglass JM: Patient outcomes for segmental colon resection according to surgeon's training, certification, and experience. Surgery 2002;132:663-670.
5 Scheidbach H, Kube R, Schmidt U, Robra BP, Gastinger I, Lippert H: Quality evaluation in colorectal surgery in dependence on health-care categories of hospitals - minor differences in outcome with room for improvement in process quality. Gesundheitswesen 2011;73:134-139.

16 Glehen O, Gilly FN, Boutitie F, Bereder JM, Quenet F, Sideris L, Mansvelt B, Lorimier G, Msika S, Elias D; French Surgical Association: Toward curative treatment of peritoneal carcinomatosis from nonovarian origin by cytoreductive surgery combined with perioperative intraperitoneal chemotherapy: a multi-institutional study of 1,290 patients. Cancer 2010;116:5608-5618.

17 Glehen O, Gilly FN, Arvieux C, Cotte E, Boutitie F, Mansvelt B, Bereder JM, Lorimier G, Quenet F, Elias D; Association Française de Chirurgie: Peritoneal carcinomatosis from gastric cancer: a multiinstitutional study of 159 patients treated by cytoreductive surgery combined with perioperative intraperitoneal chemotherapy. Ann Surg Oncol 2010;17:2370-2377.

18 Elias D, Gilly F, Quenet F, Bereder JM, Sidéris L, Mansvelt B, Lorimier G, Glehen O; Association Française de Chirurgie: Pseudomyxoma peritonei: a French multicentric study of 301 patients treated with cytoreductive surgery and intraperitoneal chemotherapy. Eur J Surg Oncol 2010;36:456-462.

19 Elias D, Gilly F, Boutitie F, Quenet F, Bereder JM, Mansvelt B, Lorimier G, Dubè P, Glehen O: Peritoneal colorectal carcinomatosis treated with surgery and perioperative intraperitoneal chemotherapy: retrospective analysis of 523 patients from a multicentric French study. J Clin Oncol 2010;28:63-68. 